\title{
Assessing the Impact of Obesity on Pregnancy and Neonatal Outcomes among Saudi Women
}

\author{
Nadia Adwani ${ }^{1}$, Howieda Fouly ${ }^{2 *}$ and Tagwa Omer ${ }^{3}$
}

\begin{abstract}
${ }^{1}$ Master degree of Midwifery, RN. Midwife at Adm Hospital - Ministry of Health, Jeddah, KSA ${ }^{2} \mathrm{PhD}$. RN, Assistant professor- Maternity Nursing, College of Nursing, King Saud Bin Abdul-Aziz University for Health Sciences, Jeddah KSA- Associate prof. Faculty of Nursing Assiut University Egypt. ${ }^{3} \mathrm{PhD}$. RN. Associate professor at Nursing College of Nursing, King Saud Bin Abdul-Aziz University for Health Sciences- Jeddah, KSA
\end{abstract}

\begin{abstract}
Background: The rising prevalence of obesity has a significant impact on obstetrics practice regarding maternal and perinatal complications includes recurrent miscarriage, pregnancy-induced hypertension, preeclampsia, gestational diabetes, and prolonged labor. Objective: To assess the impact of obesity on pregnancy and neonatal outcomes among Saudi women. Methods: The study was conducted at King Abdul-Aziz Medical City, Jeddah. Design: A cross-sectional retrospective design. A total number of 186 participants were recruited from July to Dec.2018 according to eligibility criteria. The data were collected retrospectively by a review of the chart records of the labor and delivery department. Results: The mean (SD) age of participants was 31.94(5.67) years old; two-thirds were in obesity class 1 . There was a significant association between obesity and preexisting thyroid disease and induced hypertension class3. However, episiotomy showed that obesity class 3 was significantly different from obesity class 2 . Conclusion: This study concludes obesity affects the outcomes of pregnant Saudi associations between obesity and preeclampsia, perineal tears, and episiotomy variables, and other variables reflect no associations. Recommendations: Further studies are needed to generalize the results. This study endorses the pregnant women start the antenatal follow-up from 1st trimester so, the data will be available on the system for research.
\end{abstract}

Keywords: Obesity; BMI; maternal outcomes; neonatal outcomes.

\section{Introduction}

In recent years, obesity has begun to be considered a global health problem. It is the fifth leading cause of death worldwide. Obesity is a condition of abnormal and excessive fat accumulation in adipose tissue, leading to adverse health effects. The significant contributors to weight gain, which may eventually lead to obesity, are decreased physical activity, increased dietary fat intake, and genetic factors (DeNicola et al., 2015). The rise in obesity is associated with advanced age, which becomes apparent when considering the decrease in older adults' physical activity and metabolic processes. Marital status, high educational level, alcohol use, and high socioeconomic status are other factors associated with obesity (Paul et al. 2010).

Obesity is measured using various methods, including body mass index (BMI), waist circumference (WC), waist-hip ratio, skinfold, and percent body fat measurements. BMI is the most frequently used diagnostic tool in the current classification system of obesity (Gómez-Ambrosi et al., 2012). It is calculated by dividing weight in kilograms by height in square meters. The World Health Organization (WHO) divided BMI values into six categories to define different body weights, from underweight to obesity. These categories are underweight (less than 18.5), average weight (18.5-24.9), overweight (25.0-29.9), obesity class I (30.0-34.9), obesity class II (35.0-39.9), and obesity class III (40.0 or greater) (Othman et al. 2018).

Overweight and obesity have become the most general nutritional problems globally, as they impose significant burdens on health care systems. Obesity affects 2.1 billion 
people (almost one-third) in the world. If the current trend continues, this figure may reach nearly half of the world's adult population by 2030 (Saudi guidelines 2016). Moreover, obesity is associated with multiple diseases and may result in the death of millions of people every year. Furthermore, the risk of non-communicable diseases (NCD), such as hypertension (HTN), type 2 diabetes mellitus (T2DM), dyslipidemia, and cardiovascular disease (CVD), increases dramatically with obesity. Besides, obstructive sleep apnea and osteoarthritis relate to obesity (Aljabri et al., 2018).

Females were to have a higher rate of obesity. Its prevalence doubled between 1980 and 2008 , from $8 \%$ in 1980 to $14 \%$ in 2008 . The highest incidence of overweight and obesity in 2013 was in North Africa and the Middle East, where more than $65 \%$ of reproductiveage females were overweight or obese (Aljabri et al., 2018). According to a study of overweight and obesity in Saudi women of childbearing age, the following rates of obesity were found: $22.4 \%$ were obesity class I, $11.1 \%$ were obesity class II, and $6.6 \%$ were morbidly obese (obesity class III) (Aljabri et al. 2018). Furthermore, Saudi women have exceptional obstacles that can predispose them to a sedentary lifestyle, such as the essential wearing of abaya or full-length overgarment in public, gender segregation, and activities that are primarily at home (Al-Hamdan, et al 2019; Mirabelli, Russo, \& Brunetti 2020)

Maternal obesity is one of the central risk factors for adverse pregnancy outcomes, including gestational diabetes mellitus (GDM), operative delivery, and stillbirth (Daviestuck et al. 2016). The prevalence of hypothyroidism among Saudi pregnant women is $13 \%$, most of them were in their third trimester (Al-Shanqeeti et al., 2018).

Maternal obesity increases perinatal mortality, which increases the risk of perinatal death and preterm birth, macrosomia, congenital anomaly, childhood obesity, and stillbirth. Also, maternal obesity is related to a higher risk of cesarean deliveries and a higher incidence of anesthetic and postoperative complications. Another major complication is preeclampsia, a specific syndrome characterized by new onset of hypertension with proteinuria that occurs after 20 weeks gestation. The actual cause of preeclampsia is unknown, but it is estimated to affect 2 to $8 \%$ of all pregnancies (Ali and Lakhani, 2011) (Alshahrani et al., 2018) (Jeyabalan, 2014).

The impact of obesity on pregnant women extends to the method of delivery. Previous studies reported two-thirds of $63.6 \%$ of obese women delivered by cesarean section, and there was no association between obesity or overweight and episiotomy. Obesity may be protective against the risk of third- and fourth-degree tears (Kavita et al. 2016) (BraGa et al., 2014) (Garretto et al., 2016).

Significance of the study: According to World Atlas data, Saudi Arabia is on the list of most obese countries in the world and ranked in the 15th most obese country, with an overall obesity rate of 33.7\% (M Alqarni, 2016). The prevalence of obesity in pregnant women is increasing and is associated with pregnancy-related complications and their outcomes. Moreover, obesity affects the chance of conception and might decrease the response to fertility treatment. In Saudi Arabia, $68 \%$ of pregnant women were obese (Alshahrani et al., 2018).

Even with the availability of updated data about the prevalence of obesity in Saudi Arabia, there is a lack of research conducted in Saudi Arabia about the outcome of obese pregnant women. Therefore, the study aimed to assess the impact of obesity on pregnancy and neonatal outcomes among Saudi women through the following objectives:

Describe the maternal and the neonatal outcomes for obese pregnant women, and

Compare the maternal and neonatal outcomes of obese pregnant women in different obesity classes. In addition to answering the following questions:

-What is the effect of obesity on the maternal outcomes among Saudi women?

-What is the effect of obesity on neonatal outcomes?

\section{Methods}

Study design: This study a cross-sectional cohort study retrospective design, which involves collecting data at one point in time. The phenomena of the course were captured 
during one data collection period. Cross-sectional arrangements are especially appropriate for describing the status of phenomena or relationships among phenomena at a fixed point (Davies-tuck, et al. 2016). In retrospective design, the phenomenon observed in the present is linked to phenomena occurring in the past. This study described the outcomes of obese pregnancy during the antenatal, intrapartum period, and the neonatal outcome at the delivery time.

Setting: This study was conducted in the labor room at King Khaled Hospital in Jeddah. The hospital affiliated to the Ministry of National Guard Health Affairs in the Western Region is a 600 bedded, Joint Commission International (JCI) accredited Tertiary Level Hospital. Currently, ten admission beds within the labor and delivery ( 6 beds for active labor, three beds for induction of labor, and one bed for operation room). The total number of deliveries per year was 3161 .

Participants: All obese pregnant women of primigravida and multigravida, aged from 18 to 44 years old, and the BMI for those pregnant women was 30 or more. All pregnant attended the antenatal clinic during the first trimester and delivered through expected vaginal delivery at King Khaled Hospital, "during the selected six months" of the data collection period. The study excluded all multiple pregnancies and pre-pregnant diabetes mellitus, chronic hypertension before pregnancy, had a history of cardiac diseases, or the current pregnancy with abnormal fetus lie like a breech or transverse lie. All elective cesarean sections are excluded if it is related to the different cause than obesity.

Data collection: Data was collected through a nonprobability sampling retrospectively by reviewing the chart records of the labor and delivery department. The study included all obese women who delivered in the selected six months. Then compared the outcomes of pregnancy through the different obesity' classes.

The data was collected from the chart using the BEST Care 2.0 system, founded in all the hospital computers.

Sample size: The total number of deliveries in the selected six months, during the period from $01 \backslash 07 / 2018$ to $31 \backslash 12 \backslash 2018$, was 1748 delivery. After excluding the patients of pregnant women who did not meet the criteria, the total number of patients included in this study were 186 patients, which is the total sample ( figure1)

\section{Validity and reliability}

The checklist was reviewed by eight of the nursing college's expertise and faculty members, King Saud bin Abdulaziz University for health sciences. It is validated through content and face validity, which refers to whether the instrument looks as though it measures the appropriate construct, especially to people who will be completing the tool (Polit \& Beck, 2010).

Data management: The data analyzed using the Statistical Package of Social Sciences (SPSS) version 23. Proper statistical tests were used to describe the finding of the study and to achieve the objectives of the study, with appropriate statistical measures and tests. The ordinal and nominal variables were presented in the form of frequencies and percentages. Chi-square, which is a statistical test, was used to examine the association between two quantitative variables. P-value of less than 0.05 was considered statistically significant, and it can be concluded that there is a relationship between the two variables. Fisher's exact test was performed to test the significance of the difference in proportions; it is used for small sample size or when the cells in the contingency table have no observations. Post hoc test was also used for comparing all possible pairs of groups following a significant test of overall group differences (e.g., chi-square) ( Polit and Beck 2010). 


\section{Ethical Considerations}

Ethical codes conducted are to be strictly adhered to at all stages of the study. Before implementing the project, the proposal was submitted to the College of Nursing Research unit for a review then submitted to King Abdullah International Medical Research Center (KAIMRC). The approval from KAIMARC was received for the study number SP19/114/J on (G) $21 \backslash 04 / 2019$, (H) 16th Shaban 1440. Then, the Institutional Review Board (IRB) 's approval for the research study received in $05 \backslash 05 \backslash 2019$ and valid for one year. Memo ref.NO. IRB C/0613/19, E-CTS ref.NO. JED-19-427780-71475. IRB NCBE registration No: H-01-R005. Also, the hospital agreement was obtained before data collection started.

Confidentiality, privacy, and anonymity were maintained. This study dealt with chart records, so if there is any hard copy, personal information or identities will be kept safe In a locker. This data will be held for the study for a minimum of five years and destroyed after that.

Figure. 1 Flowchart of the recruited sample

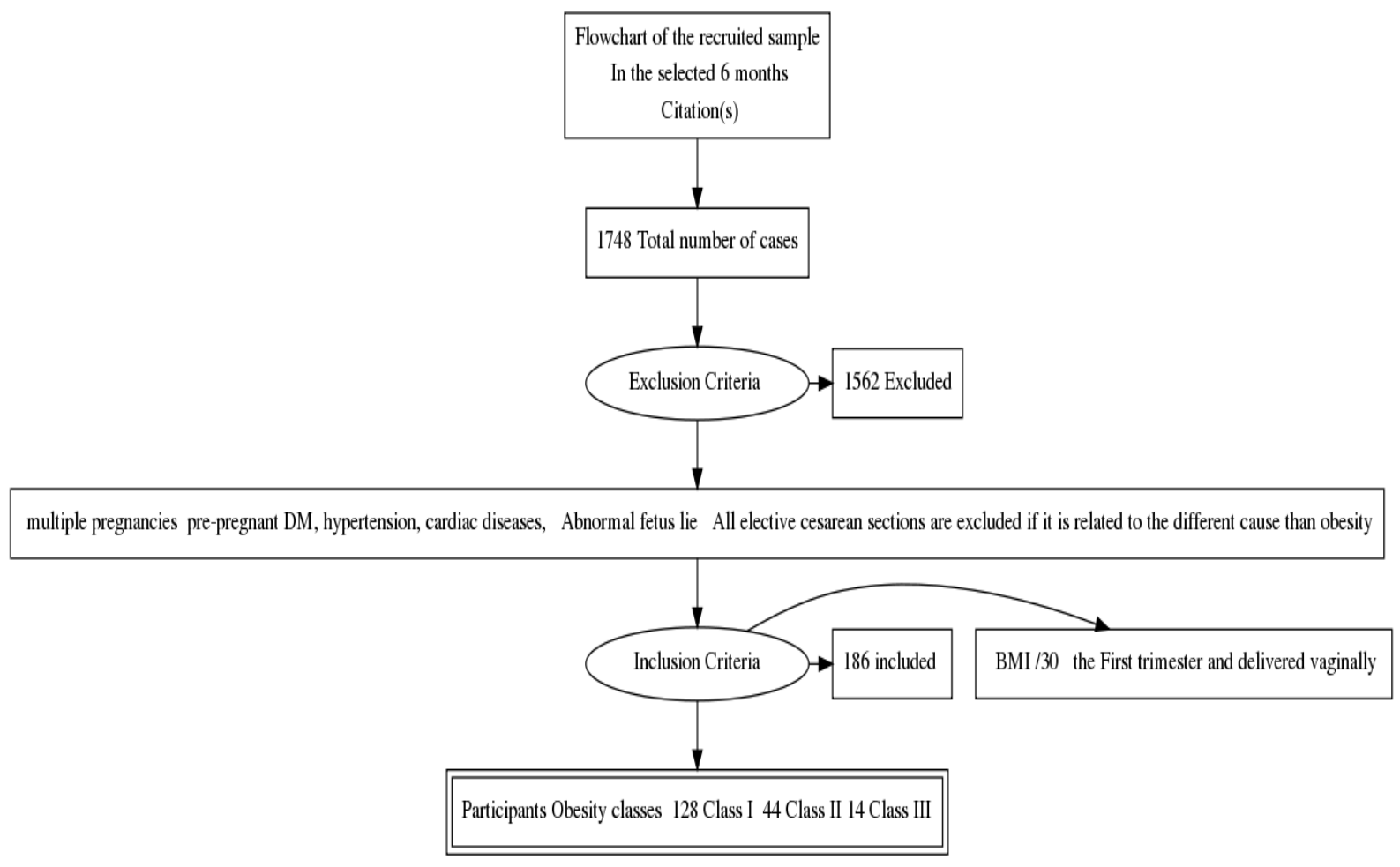




\section{Results}

Table 1 presents respondents' essential characteristics; the majority are $28.5 \%$ of women aged between 25 to 29 years, and only $12.4 \%$ for the age group between 40 to 45 years. Regarding the obstetric characteristics, results revealed that primigravida was only $16.7 \%$, while the majority were multigravida' $83.3 \%$. The mode of previous delivery $67.7 \%$ were delivered through SVD and $14.0 \%$ paid by CS. Two-thirds of women were in class1 obese (BMI 30-34), while 7.5\% of them in obesity class 3 (BMI more than 40). Regarding the risk factors, only $2.2 \%$ were smokers, $8.6 \%$ have pre-existing thyroid disease, and $5.4 \%$ had recurrent miscarriages.

Table 2 shows the frequency and result of fisher's exact test that examined the relationship between obesity classes and co-factors. The pre-existing thyroid disease shows that $16(12.5 \%)$ cases were found in obesity class1. There was a significant association between obesity and pre-existing thyroid disease at a 95\% level of confidence, and $P=0.015$. Only one case $(7.1 \%)$ and $14(92.9 \%)$ were found in class 3 obesity for preeclampsia. The association between obesity and preeclampsia at a $90 \%$ confidence level reflected no statistically significant at $P=0.075$. Similarly, there is no statistical significant difference between (GDM) and UTI with obesity. For perineal tears, intact perineal at delivery was 55 (43.0\%) cases, while $45(35.2 \%) 24(18.8 \%)$ had first and second-degree tears, respectively. For obesity class 2, 24 women (54.5\%) deliver with an intact perineum, $13(29.5 \%)$ and 4 $(9.1 \%)$ cases had $1^{\text {st }}$ and second-degree tears, respectively. In obesity class 3 , the highest percentage, $6(42.0 \%)$ deliver with intact perineal, while tears were $4(28.6 \%)$, and $(7.1 \%)$ cases had first and second-degree tears, respectively. There is a significant association between obesity and perineal tears at a $95 \%$ confidence level and $P=0.020$. The association between episiotomy and obesity reflected that class was $3(6.8 \%)$ cases out of $44(23.7 \%)$ and classIII, $3(21.4 \%)$ out of $14(7.5 \%)$ had an episiotomy. There is a significant association between obesity and episiotomy at a $95 \%$ level of confidence. The P-value of the test is 0.037 .

Table 3. shows the frequency and result of fisher's exact test that examined the relationship between obesity classes and neonatal outcomes. The gestational age categories Preterm10 (7.8) \%

Full term117 (91.4) and Post date1 (.8) relationship with obesity class I at $P<0.325$. Similarly, class II\& III reflected no statistically significant relationship. All other co-factors regarding neonatal outcomes of IUFD, Preterm babies, Apgar score, birth weight, admission to NICU, and neonatal mortality in relation to obesity classes reflected no statistical significant relationship at $(P<0.751, P<1.000, P<1.000$, and $P<0.312)$ respectively.

Table 4 . Shows the result of post-hoc tests that were conducted to test pairwise comparisons. The finding indicates that Pre-existing thyroid disease compared to obesity class1 was significantly different from obesity class2 $(p=0.033)$. Obesity class 1 and obesity class3, and both obesity class2 and class3 were not significantly different.

The comparison of induced hypertension shows that obesity class 3 was significantly different from obesity class1 $(p=0.001)$. Furthermore, obesity class 3 was significantly different from obesity class2 $(p=0.001)$. On the other hand, obesity class1 and class2 were not significant in regard to induced hypertension. The finding of perineal tears shows that obesity class 1 was significantly different from obesity class3 $(p=0.020)$. Either obesity class 1 and obesity class 2 or obesity class 2 and class 3 were not significantly different. The result of episiotomy shows that obesity class 3 was significantly different from obesity class2 $(p=0.044)$. Also, obesity class 3 was significantly different from obesity class $1(p=$ 0.008 ). Besides, there is no statistically significant difference between obesity class 2 and class1.

\section{Discussion}

The rising prevalence of obesity has a significant impact on obstetrics practice. Maternal complication association due to obesity includes recurrent miscarriage, pregnancy-induced hypertension, preeclampsia, gestational diabetes, prolonged labor, and increased risk of interventions like induction of labor, operative delivery, shoulder dystocia, 
and postpartum hemorrhage (Sinha et al. 2018). On the other hand, perinatal complications include congenital disabilities like congenital anomalies, macrosomia, stillbirth, preterm birth, and the need for admission to the neonatal intensive care unit (Sinha et al., 2018).

Our study aimed to assess the impact of obesity on pregnancy and neonatal outcomes among Saudi women. This study's first objective was to describe the pregnancy and the neonatal outcomes for obese pregnant women. The present study revealed a significant association between obesity and pre-existing thyroid disease, pregnancy-induced hypertension (preeclampsia), perineal tears, and episiotomy.

Regarding the association between obesity and pre-existing thyroid disease, our result shows a statistically significant association between obesity and pre-existing thyroid disease. Similarly, in a prospective cohort study (Collares et al. 2017) conducted at Rotterdam, the Netherlands. The study aimed to examine maternal thyroid function associations in early pregnancy with maternal BMI and weight gain during pregnancy. This study identified a higher maternal TSH level in early pregnancy associated with a higher pre-pregnancy BMI and an increased risk of excessive gestational weight gain. In contrast, a higher maternal FT4 level was associated with a lower pre-pregnancy BMI and a lower risk of excessive gestational weight gain. Associations of maternal thyroid function with gestational weight gain were strongest for weight gain in early pregnancy. Also, (Pop et al. 2013), in a prospective follow-up study of thyroid parameters and gestational weight gain, indicated that higher median TSH and lower median FT4 levels in all trimesters were correlated with a higher amount of total weight gain during pregnancy.

Conversely, a study conducted at Baylor aimed to measure T3, fT4, and TSH in maternal and matched cord blood serum from average weight, overweight and obese gravidae to determine alterations in maternal and neonatal TH levels by maternal obesity. The result showed no significant difference in gestational age and weight gain (Kahr et al., 2016).

Regarding the association between obesity and preeclampsia, our result shows a statistically significant association between obesity and preeclampsia, similarly, in prospective cohort research conducted in Jeddah Maternity and Children Hospital (MCH). The study revealed a positive association between obesity and increased risk of pregnancy-induced hypertension and preeclampsia compared with the normal-weight women. A previous study by Zayed et al. (2018) conducted in Tabuk City found a higher risk of preeclampsia in obese non-GDM women.

Likewise, (Young et al. 2016) demonstrated in the retrospective cohort study that women with pre-pregnancy obesity are more likely to develop preeclampsia, which reported a statistically significant association between obesity and preeclampsia.

According to Marchi et al. 2015), in a review that aimed to summarize the findings of published systematic reviews regarding the possible risks for pregnant women with obesity and their infants. The review demonstrates an association between obesity and gestational hypertension and preeclampsia, identified as a risk factor in 54 studies.

A cohort study was done by Paré (2014), where data was collected from three large urban academic centers; the result revealed a positive association between obesity and preeclampsia. Moreover, a study by (Salihu et al. 2012) reported in the systematic literature review of two decades (1992-2011) that obesity is associated with preeclampsia or hypertension during pregnancy.

On the other hand, the findings reported by Gaillard et al. 2016 in a prospective cohort study, the result shows that higher gestational weight gain was associated with a higher risk of pregnancy-induced hypertension but not with preeclampsia. Additionally, higher pre-pregnancy BMI is associated with high blood pressure, both systolic and diastolic, in all trimesters.

Regarding perineal tears, our result shows a statistically significant association between obesity and perineal tears. the association between these two variables is a significant negative association, which means when the obesity class decreases, the risk for 
perineal tears increased. Conversely, when the obesity class increased, the risk for perineal tears decreased.

Similarly, Garretto et al. 2016 in the case-control study, revealed no significant association between obesity and perineal tears. Likewise, a previous cohort study by Blomberg, 2014 which demonstrated that the risk of partial anal sphincter injury or total sphincter injury and fourth-degree perineal tears decreased with maternal obesity. The general risk for any anal sphincter injury among obese women class 3 was reduced by $25 \%$ compared to normal women's weight.

Previous studies found that obese women have a lower risk for perineal tears, known as a protective effect of obesity. The negative association between obesity and perineal tears has shown that obesity in pregnancy is not commonly associated with adverse events (Durnea et al., 2017).

Al-ghamdi et al. 2018 in a retrospective cohort study conducted in Riyadh, Saudi Arabia, indicated an association between obesity and perineal tears. Furthermore, the prospective cohort study by (Kamel et al. 2018), which was carried out in Egypt, reported that obese women had a higher perineal tear rate, mostly second-degree tearing, than those with normal BMI. Besides, there was no significant difference in the incidence of thirddegree perineal tear in obese women.

In the same line, Lindholm and Altman (2013) found that the rate of third- and fourth-degree perineal tears decreased with increasing BMI, whereas the opposite was true for first- and second-degree perineal tears, which increased with increasing BMI.

In conclusion, the incongruence between our study and those studies may be due to the large study population, and the data included an ethnically heterogeneous population.

Regarding episiotomy, our result shows a statistically significant association between obesity and episiotomy. Dissimilarly, the case-control study was conducted on pregnant women and reported no association between obesity and episiotomy. (BraGa et al., 2014).

In the same line, a study done by Anzaku, Idikwu, \& Emmanuel (2015) reported in a prospective cohort study conducted at Bingham. that there was no increased risk of episiotomy/perineal tear among obese pregnant women.

Similarly, a systematic review and meta-analysis were conducted to investigate maternal obesity in Africa by (Onubi et al. 2015) and reflected no significant relationship between maternal obesity and episiotomy or perineal tear. The contrast between our study and those studies may be due to the ethnically heterogeneous population.

This study's second objective was to compare the pregnancy and the neonatal outcomes of obese pregnant women in different obesity classes. Regarding preeclampsia, our study's findings were in accordance with other findings reported by (Young, et al 2016), which stated that preterm preeclampsia is high in women with class III obesity compared to normal-weight women. This agrees with only one case in our study, which was categorized under obesity class3.

Several previous studies (Othman et al. 2018; Zayed et al. 2017; Marchi et al. 2015; Salihu et al. 2012; Blomberg et al. 2014; Onubi et al. 2016) reflected their result based on a comparison of obesity in general with average weight not like our study the comparison in obesity classes.

Obese women have an increased risk of gestational diabetes and giving birth to macrosomic children regardless of their glycemic status. In order to limit the pregnancy complications of obesity, it is common obstetric practice to restrict weight gain in obese women with diet/physical exercise. These factors may have influenced the fetal growth, and thus, the consequent risk of perineal tears/episiotomy/cesarean sections. In this study, neither the prevalence rates of gestational diabetes nor the amount of gestational weight gain were addressed ( Chiefari, et al 2020; Quaresima, et al 2020)

\section{Limitation of the study:}


Missing data inpatient medical record led to exclude the patients from the sample. The exclusion criteria decrease the sample size, which affects reversibility. Also, the lack of a normal-weight control group would have provided the baseline rates of obstetrical complications in Saudi women, which is not included in our study.

Generalizability: To find the relationship between obesity and labor outcome, the study needs to extend and be conducted on a larger sample to generalized in the future.

\section{Conclusion \& Implication for future practice}

The study sheds light on a significant risk factor among Saudi pregnant women as obesity is a severe public health problem and harms maternal pregnancy outcomes. This study reflected several associations between obesity and specific co-factors as preeclampsia, perineal tears, and episiotomy variables. Consequently, the findings of the study draw a primary direction of essential data that should be included in the care system to prevent the future complication of obesity among pregnant women

Recommendations: Further studies are needed to conduct a larger sample size and include the elective cesarean section and its relation to obesity. This study encourages the broadness of data to have all Jeddah districts, not only one point, and increases the data collection period to generalize the results. The study also recommends the pregnant women start the antenatal follow-up from 1st trimester so that the data will be available on the research system.

Funding: No source of funding 


\section{References}

Al-ghamdi, T., Chamsi, A. T., \& Mardawi, E. Al. (2018). Incidence and Risk Factors for Development of Third and Fourth Degree Perineal Tears: A Four Year Experience in a Single Saudi Center Journal of Women's Health Care, 7(2), 2-5. https://doi.org/10.4172/2167-0420.1000423

Al-Hazzaa H. M. (2018). Physical inactivity in Saudi Arabia revisited: A systematic review of inactivity prevalence and perceived barriers to active living. International journal of health sciences, 12(6), 50-64.

Al-Hamdan, R., Avery, A., Salter, A., Al-Disi, D., Al-Daghri, N. M., \& McCullough, F. (2019). Identification of Education Models to Improve Health Outcomes in Arab Women with Pre-Diabetes. Nutrients, 11(5), 1113. doi:10.3390/nu11051113

Aljabri, K. S., Bokhari, S. A., Khan, Alshareef, Ebu Elsaoud, H. M., Aljabri, B. K., Boraie, R. E. . (2018). Overweight and Obesity in Saudi Women of Childbearing Age. Ec Endocrinology and Metabolic Research, 3 (2): 53-62 2

Al Shanqeeti, S. A., Alkhudairy, Yasser N., Alabdulwahed, A.A. Ahmed, A.E., Al-Adham, M. S., Mahmood, N. M.(2018). Prevalence of subclinical hypothyroidism in pregnancy in Saudi Arabia. Saudi Med J 2018; Vol. 39 (3):254-260. doi: 10.15537/smj.2018.3.21621

Anita Zutshi, Jayasree Santhosh, Julie Sheikh, Fareeha Naeem, Ahmed Al-Hamedi, Shahla Khan, E. A.-S. (2018). Implications of Early Pregnancy Obesity on Maternal, Fetal and Neonatal Health, 18(February), 47-53. https://doi.org/10.18295/squmj.2018.18.01.008

Anzaku, A. S., Idikwu, O. G., \& Emmanuel, O. A. (2015). Impacts of Obesity on Maternal and Fetal Outcomes in Women with Singleton Pregnancy at a Nigerian Clinical Setting Impacts of Obesity on Maternal and Fetal Outcomes in Women with Singleton Pregnancy at a Nigerian Clinical Setting, (January 2016). https://doi.org/10.9734/BJMMR/2015/15618

Blomberg, M. (2014). Maternal Body Mass Index and Risk of Obstetric Anal Sphincter Injury, 2014.

BraGa, G. C., ClemenTino, suelem T. pereira, Luz, paTríCia F. neves da, SCavuzzi, A., NeTo, C. noronha, \& Amorim, melania maria ramos. (2014). Risk factors for episiotomy : a case-control study, 60(5), 465-472.

Chiefari, E., Quaresima, P., Visconti, F., Mirabelli, M., \& Brunetti, A. (2020). Gestational diabetes and fetal overgrowth: time to rethink screening guidelines. The lancet. Diabetes \& endocrinology, 8(7), 561-562. https://doi.org/10.1016/S2213-8587(20)30189-3

Collares, F. M., Korevaar, T. I. M., Hofman, A., Steegers, E. A. P., Peeters, R. P., \& Jaddoe, V. W. V. (2017). Maternal thyroid function, pre-pregnancy obesity and gestational weight gain - The Generation R Study : A prospective cohort study, (May), 799-806. https://doi.org/10.1111/cen.13412

Constantin M. Durnea, Ali E. Jaffery, Nivedita Gauthaman, S. K. D. (2014). Effect of body mass index on the incidence of perineal trauma. https://doi.org/10.1111/ijlh.12426

Davies-tuck, M., Mockler, J. C., Stewart, L., Knight, M., \& Wallace, E. M. (2016). Obesity and pregnancy outcomes : Do the relationships differ by maternal region of birth? A retrospective cohort study. BMC Pregnancy and Childbirth, 1-8. https://doi.org/10.1186/s12884-016-1087-5

DeNicola, E., Aburizaiza, O. S., Siddique, A., Khwaja, H., \& Carpenter, D. O. (2015). Obesity and public health in the Kingdom of Saudi Arabia. Reviews on Environmental Health, 30(3), 191-205. https://doi.org/10.1515/reveh-2015-0008

E. S. Lindholm and D. Altman. (2013). "Risk of obstetric anal sphincter lacerations among obese women," BJOG: An International Journal of Obstetrics \& Gynaecology, vol. 120, no. 9, pp. 1110-1115, 2013.

Gaillard, R., Steegers, E. A. P., Hofman, A., \& Jaddoe, V. W. V. (2011). Associations of maternal obesity with blood pressure and the risks of gestational hypertensive disorders . The Generation R Study, 937-944. https://doi.org/10.1097/HJH.0b013e328345500c

Garretto, D., Lin, B. B., Syn, H. L., Judge, N., Beckerman, K., Atallah, F., Bernstein, P. S. (2016). Obesity May Be Protective against Severe Perineal Lacerations, 2016.

Gómez-Ambrosi, J., Silva, C., Galofré, J. C., Escalada, J., Santos, S., Millán, D., ... Frühbeck, G. (2012). Body mass index classification misses subjects with increased cardiometabolic risk factors related to elevated adiposity. International Journal of Obesity, 36(2), 286-294. https://doi.org/10.1038/ijo.2011.100

Kahr, M. K., Antony, K. M., Delbeccaro, M., Hu, M., Aagaard, K. M., \& Suter, M. A. (2016). Increasing maternal obesity is ass ociated with alterations in both maternal and neonatal thyroid hormone levels, 551-557. https://doi.org/10.1111/cen.12974

Kamel, H. A. H., Ibrahim, A. S. M., \& Abdo, M. M. (2018). Maternal Obesity and Its Effect in Late Pregnancy and Labour, 71(April), 2982-2988.

Kavita Sinha, Subhash Pandey, C. R. Das. (2016). Impact of Maternal Obesity on Pregnancy Outcome, (October 2018). https://doi.org/10.3126/jngmc.v14i2.21531

Mirabelli, M., Russo, D., \& Brunetti, A. (2020). The Role of Diet on Insulin Sensitivity. Nutrients, 12(10), 3042. doi:10.3390/nu12103042

Marchi, J., Berg, M., Dencker, A., Olander, E. K., \& Begley, C. (2015). Risks associated with obesity in pregnancy, for the mother and baby: A systematic review of reviews. Obesity

Musaiger, A. O. (2011). Overweight and obesity in Eastern Mediterranean Region: Prevalence and possible causes. Journal of Obesity, 2011(May). https://doi.org/10.1155/2011/407237

Othman, M., Himayda, S. S., \& Shaaban, L. (2018). Obesity and Pregnancy in Saudi Women. Arch Clin Med Case Rep, 2(2), 50-55. https://doi.org/10.26502/acmcr.96550024

Onubi, O. J., Marais, D., Aucott, L., Okonofua, F., \& Poobalan, A. S. (2015). Maternal obesity in Africa : a systematic review and metaanalysis, 38(3). https://doi.org/10.1093/pubmed/fdv138

Paul, E., Mtumwa, A. H., Ntwenya, J. E., \& Vuai, S. A. H. (2016). Disparities in Risk Factors Associated with Obesity between Zanzibar and Tanzania Mainland among Women of Reproductive Age Based on the 2010 TDHS, 2016. 
Paré, E., Parry, S., Newton, A., Lim, K., Mcelrath, T. F., \& Pucci, D. (2014). Clinical Risk Factors for Preeclampsia in the 21st Century, 124(4), 763-770. https://doi.org/10.1097/AOG.0000000000000451

Polit, D. ., \& Beck, C. T. (2010). Essentials of Nursing Research Evidence for Nursing Practice.

Pop VJ, Biondi B, Wijnen HA, Kuppens SM, Lvader H (2013). Maternal thyroid parameters, body mass index, and subsequent weight gain during pregnancy in healthy euthyroid women. Clin Endocrinol (Oxf). 2013;79:577-583.

Quaresima, P., Visconti, F., Chiefari, E., Mirabelli, M., Borelli, M., Caroleo, P., Foti, D., Puccio, L., Venturella, R., Di Carlo, C., \& Brunetti, A. (2020). Appropriate Timing of Gestational Diabetes Mellitus Diagnosis in Medium- and Low-Risk Women: Effectiveness of the Italian NHS Recommendations in Preventing Fetal Macrosomia. Journal of diabetes research, 2020, 5393952. https://doi.org/10.1155/2020/5393952

Salihu, H. M., Cruz, C. D. La, Rahman, S., \& August, E. M. (2012). Does maternal obesity cause preeclampsia? A systematic review of the evidence (May 2014).

Saudi guidelines on prevention and management of obesity./ Ministry of health - Riyadh ,(2016). 51p;..cm ISBN : 978-603-8174-89-0

Saudi Ministry of Health. The National Guidelines for Management of Cardio-metabolic Risk Factors in Primary Health care, 2014

Young, O. M., Twedt, R., \& Catov, J. M. (2016). Prepregnancy Maternal Obesity and the Risk of Preterm Preeclampsia in the American Primigravida, 24(6), 1226-1229. https://doi.org/10.1002/oby.21412.

Zayed, E. S., Allah, R. K. F., Shaman, A. A., Yousef, R. S., Elsaifi, O., \& Bakheit, K. H. (2018). The Effects of Maternal Obesity and Gestational Diabetes on the Pregnancy Outcomes

(HAPO) In Saudi Women, At Tabuk City, https://doi.org/10.7537/marslsj141017.04 


\section{Results}

Tables

Table 1 The Sociodemographic characteristics of study's participants.

\begin{tabular}{|c|c|c|c|}
\hline Variable & categories & $\mathrm{N}=186$ & $\%$ \\
\hline \multirow[t]{5}{*}{ Age } & Less 24 & 15 & 8.1 \\
\hline & $25-29$ & 53 & 28.5 \\
\hline & $30-34$ & 50 & 26.9 \\
\hline & $35-39$ & 45 & 24.2 \\
\hline & $40-45$ & 23 & 12.4 \\
\hline Primigravida & Yes & 31 & 16.7 \\
\hline Multigravida & Yes & 155 & 83.3 \\
\hline \multirow[t]{2}{*}{ Previous delivery } & SVD (Spontaneous vaginal delivery) & 126 & 67.7 \\
\hline & CS (Caesarean section) & 26 & 14.0 \\
\hline \multirow{4}{*}{ Obesity } & (Primigravida) & 31 & 16.7 \\
\hline & Class1(BMI 30-34) & 128 & 68.8 \\
\hline & Class2(BMI 35-39) & 44 & 23.7 \\
\hline & Class3(BMI more than 40) & 14 & 7.5 \\
\hline Current Smoking & Yes & 4 & 2.2 \\
\hline \multirow{5}{*}{$\begin{array}{l}\text { Pre-existing thyroid disease } \\
\text { Recurrent miscarriages }\end{array}$} & No & 182 & 97.8 \\
\hline & Yes & 16 & 8.6 \\
\hline & No & 170 & 90.4 \\
\hline & Yes & 10 & 5.4 \\
\hline & No & 176 & 93.6 \\
\hline
\end{tabular}


Table 2. Association between Obesity and obstetrics co-factors

*Statistically significant $P<0.05$

\begin{tabular}{|c|c|c|c|c|}
\hline & \multicolumn{4}{|c|}{ Obesity } \\
\hline & $\begin{array}{l}\text { Class } 1 \\
(\mathrm{BMI} 30-34 \mathrm{~kg} / \mathrm{m} 2) \\
\mathrm{n}=128(\%)\end{array}$ & $\begin{array}{l}\text { Class } 2 \\
(\text { BMI } 35-39.9 \mathrm{~kg} / \mathrm{m} 2) \\
\mathrm{n}=44(\%)\end{array}$ & $\begin{array}{l}\text { Class } 3 \\
(\mathrm{BMI} \geq 40.0 \mathrm{~kg} / \mathrm{m} 2) \\
\mathrm{n}=14(\%)\end{array}$ & P value* \\
\hline $\begin{array}{l}\text { Pre-existing thyroid disease } \\
\text { Yes } \\
\text { No }\end{array}$ & $\begin{array}{l}16(12.5) \\
112(87.5\end{array}$ & $\begin{array}{l}0 \\
44(100) \\
\end{array}$ & $\begin{array}{l}0 \\
14(100)\end{array}$ & $0.015^{*}$ \\
\hline $\begin{array}{l}\text { Pregnancy induced hypertension } \\
\text { Yes } \\
\text { No }\end{array}$ & $\begin{array}{l}0 \\
128(100)\end{array}$ & $\begin{array}{c}0 \\
44(100)\end{array}$ & $\begin{array}{l}1(7.1) \\
13(92.9)\end{array}$ & 0.075 \\
\hline $\begin{array}{l}\text { Gestational diabetes } \\
\text { Yes } \\
\text { No }\end{array}$ & $\begin{array}{l}29(22.7) \\
99(77.3)\end{array}$ & $\begin{array}{l}12(27.3) \\
32(72.7)\end{array}$ & $\begin{array}{l}12(27.3) \\
32(72.7)\end{array}$ & 0.624 \\
\hline $\begin{array}{l}\text { Urinary tract infection } \\
\text { Yes } \\
\text { No }\end{array}$ & $\begin{array}{l}1(.8) \\
127(99.2)\end{array}$ & $\begin{array}{c}1(2.3) \\
43(97.7)\end{array}$ & $\begin{array}{l}0 \\
14(100)\end{array}$ & 0.528 \\
\hline $\begin{array}{l}\text { Perineal tear } \\
\text { First degree } \\
\text { Second degree } \\
\text { Third degree } \\
\text { Intact }\end{array}$ & $\begin{array}{l}45(35.2) \\
24(18.8) \\
1(.8) \\
55(43.0)\end{array}$ & $\begin{array}{l}13(29.5) \\
4(9.1) \\
0 \\
24(54.5)\end{array}$ & $\begin{array}{l}1(7.1) \\
4(28.6) \\
0 \\
6(42.9)\end{array}$ & $0.020^{*}$ \\
\hline $\begin{array}{l}\text { Episiotomy } \\
\text { Yes } \\
\text { No }\end{array}$ & $\begin{array}{l}5(3.9) \\
123(96.1)\end{array}$ & $\begin{array}{l}3(6.8) \\
41(93.2\end{array}$ & $\begin{array}{l}3(21.4) \\
11(78.6)\end{array}$ & $0.037 *$ \\
\hline $\begin{array}{l}\text { Induction of Labor } \\
\text { Augmentation of labor }\end{array}$ & $\begin{array}{l}33(25.8) \\
26(20.3)\end{array}$ & $\begin{array}{l}11(25.0) \\
9(20.5)\end{array}$ & $\begin{array}{l}5(35.7) \\
6(42.9)\end{array}$ & $\begin{array}{l}0.730 \\
0.163\end{array}$ \\
\hline $\begin{array}{l}\text { Method of Delivery } \\
\text { spontaneous vaginal delivery (SVD) } \\
\text { Instrumental } \\
\text { Caesarean section (CS) }\end{array}$ & $\begin{array}{l}97(75.8) \\
8(6.3) \\
23(18.0)\end{array}$ & $\begin{array}{l}31(70.5) \\
2(4.5) \\
11(25.0)\end{array}$ & $\begin{array}{l}9(64.3) \\
0 \\
5(35.7)\end{array}$ & $\begin{array}{l}0.505 \\
0.112\end{array}$ \\
\hline $\begin{array}{l}\text { Labor complications } \\
\text { postpartum haemorrhage } \\
\text { Yes }\end{array}$ & $3(2.3)$ & $1(2.3)$ & $1(7.1)$ & 0.399 \\
\hline
\end{tabular}


* Statistically significant $P<0.05$

\begin{tabular}{|c|c|c|c|c|}
\hline & \multicolumn{4}{|c|}{ Obesity } \\
\hline & $\begin{array}{l}\text { Class } 1 \\
(\text { BMI 30-34 } \\
\mathrm{kg} / \mathrm{m} 2) \quad \mathrm{n}=128 \\
(\%)\end{array}$ & $\begin{array}{l}\text { Class } 2 \\
(\mathrm{BMI} 35.0- \\
39.9 \mathrm{~kg} / \mathrm{m} 2) \\
44(\%)\end{array}$ & $\begin{array}{l}\text { Class } 3 \\
(\mathrm{BMI} \geq 40.0 \mathrm{~kg} / \mathrm{m} 2) \\
\mathrm{n}=14(\%)\end{array}$ & $\mathrm{P}$ value* \\
\hline $\begin{array}{l}\text { Gestational age } \\
\text { Preterm } \\
\text { Full term } \\
\text { Post date }\end{array}$ & $\begin{array}{l}10(7.8) \\
117(91.4) \\
1(.8)\end{array}$ & $\begin{array}{l}3(6.8) \\
41(93.2) \\
0\end{array}$ & $\begin{array}{l}0 \\
13(92.9) \\
1(7.1)\end{array}$ & 0.325 \\
\hline $\begin{array}{c}\text { IUFD } \\
\text { Preterm baby }\end{array}$ & $\begin{array}{l}0 \\
10(7.8)\end{array}$ & $\begin{array}{l}1(2.3) \\
3(6.8)\end{array}$ & $\begin{array}{l}0 \\
0\end{array}$ & $\begin{array}{l}0.312 \\
0.894\end{array}$ \\
\hline $\begin{array}{l}\text { APGAR score } \\
0-2 \text { need resuscitation } \\
\text { 3-6 stimulation } \\
\text { 7-10 no action }\end{array}$ & $\begin{array}{l}1(.8) \\
3(2.3) \\
124(96.9)\end{array}$ & $\begin{array}{l}1(2.3) \\
1(2.3) \\
42(95.5)\end{array}$ & $\begin{array}{l}0 \\
0 \\
14(100)\end{array}$ & 0.751 \\
\hline $\begin{array}{l}\text { Birth weight } \\
\text { AGA (Appropriate for gestational } \\
\text { age) } \\
\text { SGA (Small for gestational age) } \\
\text { LGA (Large for gestational age) }\end{array}$ & $\begin{array}{l}108(84.4) \\
12(9.4) \\
8(6.3)\end{array}$ & $\begin{array}{l}38(86.4) \\
4(9.1) \\
2(4.5)\end{array}$ & $\begin{array}{l}13(92.9) \\
1(7.1) \\
0\end{array}$ & 1.000 \\
\hline Admission to NICU & $4(3.1)$ & $1(2.3)$ & 0 & 1.000 \\
\hline Neonatal mortality & 0 & $1(2.3)$ & 0 & 0.312 \\
\hline & & & & \\
\hline
\end{tabular}

** Statistically significant $P<0.01$

Table 4 Comparison of obesity classes within Pre-existing thyroid disease: 


\begin{tabular}{|lc|l|}
\hline $\begin{array}{l}\text { Obesity } \\
\text { disease }\end{array}$ & Pre-existing thyroid & P.value \\
& \multicolumn{1}{|c|}{ Test Statistic } & \\
\hline Class1-class2 & -11.625 & $.033^{*}$ \\
Class1-class3 & -11.625 & .343 \\
Class2-class3 & 0.000 & 1.000 \\
\hline Obesity & Induced Hypertension & P.value \\
& 6.643 & \\
\hline Class3-class1 & 6.643 & $.001^{*}$ \\
Class3-class2 & 0.000 & $.001^{* *}$ \\
Class1-class2 & Perineal tears & 1.000 \\
\hline Obesity & Test Statistic & P.value \\
\hline Class1-class2 & -14.077 & .108 \\
Class1-class3 & -32.876 & $.020^{*}$ \\
Class2-class3 & -18.799 & .222 \\
\hline Obesity & Episiotomy & P.value \\
Test Statistic & & \\
\hline Class3-class2 & 13.588 & .044 \\
Class3-class1 & 16.296 & $.008^{*}$ \\
Class2-class1 & 2.708 & 0.481 \\
\hline
\end{tabular}

* Statistically significant $P<0.05$

** Statistically significant $P<0.01$ 